\title{
Web-based fiber optic communications course
}

\author{
Joseph Palais
}

Joseph C. Palais, "Web-based fiber optic communications course," Proc. SPIE 4588, Seventh International Conference on Education and Training in Optics and Photonics, (28 May 2002); doi: 10.1117/12.468752

SPIE Event: Education and Training in Optics and Photonics 2001, 2001, Singapore, Singapore 


\title{
A Web-based fiber-optic communications course
}

\author{
Joseph C. Palais* \\ Arizona State University, Department of Electrical Engineering, Tempe, AZ 85287-5706
}

\begin{abstract}
In the last few years, there have been more and more College and University engineering cours es appearing on the Web. Most of the instructors producing these Web courses have not only never done so before, they have not even taken or viewed a Web class before. Because of this, it is helpful to share as many details as possible about Web courses actually presented. This paper describes a Web course on fiber-optic communications presented to a class of 55 students at the senior/first-year-graduate level.
\end{abstract}

Keywords : fiber optics, web classes

\section{INTRODUCTION}

Numerous Web classes are now being offered and many more are being developed. We expect this trend to continue for some time. A Web class is defined as a course where most of the course material and much of the interaction between student and instructor is on the Web. In a Web class, conventional face-to-face lectures are replaced by recorded lectures and/or textual material available to the student over the Internet. Excluded from this definition are what may be called Web-enhanced courses, where course materials (such as reading and homework assignments) can be found on the Web but the major student-instructor interaction is the classroom meeting. There are many variations possible for Web presentations, some still being developed. This paper describes a senior/first-year graduate Web course in fiber optic communications. I hope the experiences described will help others in constructing their own Web courses.

\section{COURSE MATERIAL}

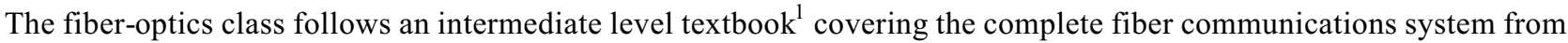
transmitter to receiver, as illustrated in Fig.1. The course material describes both system and component issues. Topics include fiber communications systems, propagation in dielectric waveguides, dispersion, integrated optic waveguides, single-mode and multimode optical fibers, attenuation in fibers, fiber bandwidth and data rate limitations, fiber construction, light sources, optical amplifiers, and photodetectors.

The fiber course has been taught since the Fall 1979 semester. Initially it was taught in a conventional classroom using chalk and a blackboard. In Fall 1984 it migrated to a televised version. Students attended class in the TV studio, but lectures were written on a pad whose image the students could view on TV monitors in the classroom and at remote TV sites. The course was broadcast to industrial sites in the Phoenix area. The next change occurred in Fall 1995 when the course was picked up by the National Technological University (NTU) as part of their satellite distribution of televised courses. In Fall 2000, the course was presented for the first time on the Internet. (I wonder what the next progression will be in, say, the year 2010). The long course history provides a base upon which to judge the success and viability of the Web version.

\footnotetext{
*joseph.palais@asu.edu
} 


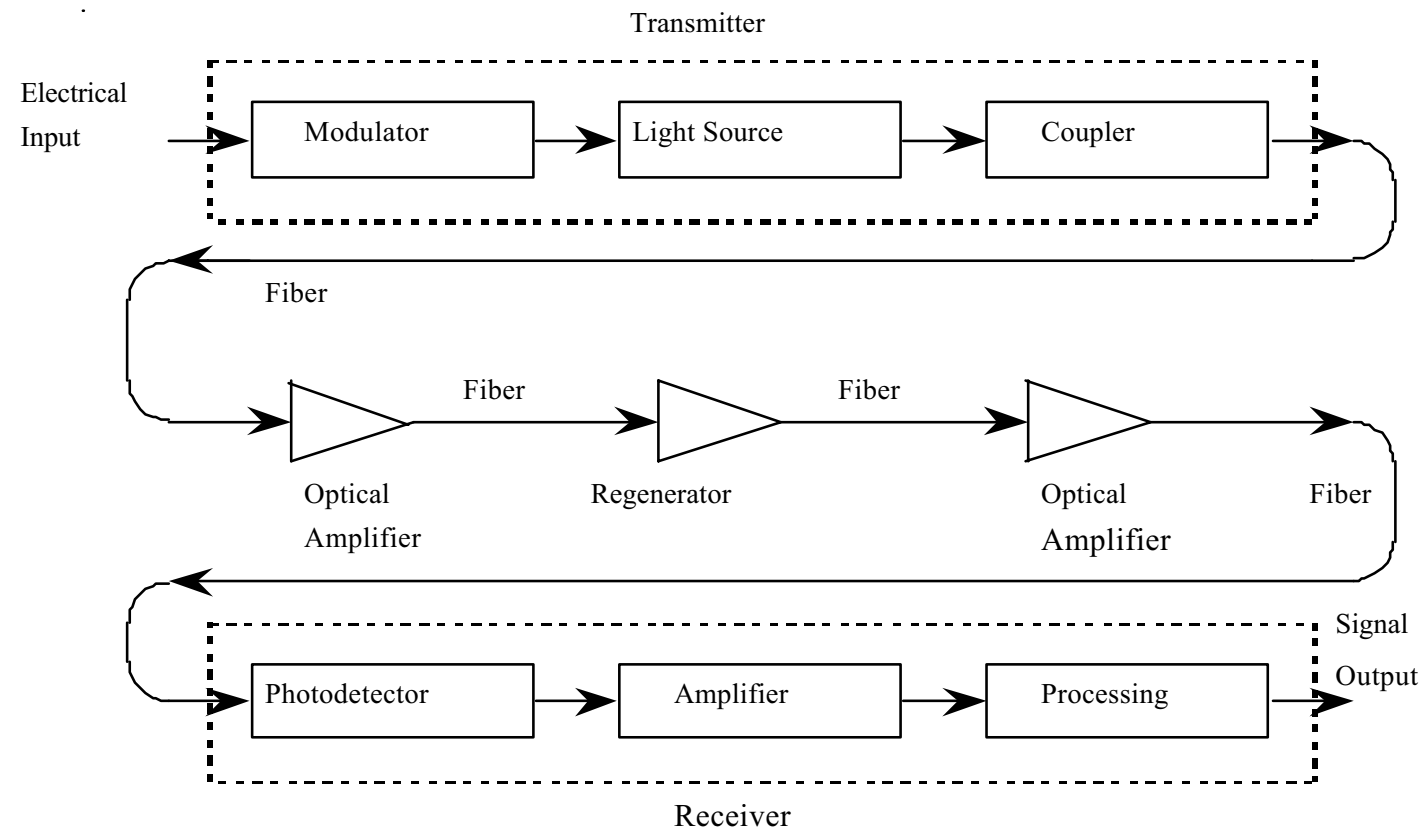

Figure 1. Fiber-optic communications system.

\section{TECHNOLOGY}

Lectures that were very similar to those delivered in the face-to-face environment were recorded. The technology for producing the online material was a combination of Blackboard and Tegrity Web Learner. Blackboard was used for course management and Tegrity WebLearner for synchronizing audio with PowerPoint slides for streaming lectures on the Internet. Lectures were recorded and archived without students present. The students view the PowerPoint slides while listening to the recorded lecture. The slides are available for downloading by the student. Students normally first download the slides and then play the lecture. Students can annotate the slides while they listen to the lecture.

The files were compressed for viewing using a $28 \mathrm{~K}$ modem connection. The viewer needs Windows Media Player for playback of the lectures. Students access the course through a University portal. This portal was ASUOnline in Fall 2000 and changed to myASU in Fall 2001.

The lectures were recorded in short segments on the order of 10 to 15 minutes each. This provided a great deal of flexibility for the viewing student.

Although the Tegrity system permits recording images of the instructor together with the audio and PowerPoint slides, this feature was turned off except for a prologue and an epilog. It was felt that instructor images do not add much to lectures in a technical course such as the fiber course. Additionally, the image movement was a little jerky. The name and a still photograph of the instructor did appear on the first page of each major section to remind the student who was giving the lectures.

\section{STUDENT OUTCOMES}

Advantages of the Web system cited by students included the following:

- Lectures could be viewed at any time.

- Lectures could be viewed at a place of student choosing.

- Lectures could be replayed totally or in parts. 
- Printed notes were provided, reducing note taking.

- Links to useful Web sites were included to enlarge the information base available to the students.

Interviews indicate that the great flexibility associated with Web classes is an overriding factor in their acceptance by students.

Disadvantages of the system include:

- The transmission was sometimes slow. This was caused by server overloading.

- Unreliable access to the course material. On several occasions the servers were shut down completely.

- Student unfamiliarity with the hardware and software required.

- The required resources are large. Costs include acquisition of hardware and software for recording, including servers with appropriate capacities and reliability. Additional funds are needed for people to operate the systems and help with preparation of the course materials.

- Faculty time for preparation and maintenance of a Web class far exceeds the time required for a conventional class.

The server problems have been addressed and the problems associated with them have diminished. With time and practice, students (as well as faculty) have become more comfortable and proficient with the technology.

An assessment of the course revealed that student grades were comparable to the grades earned in the previous, nonWeb, versions of the class. Student satisfaction was high, indicating acceptance of the Web form of class presentation.

\section{CONCLUSIONS}

The class results were quite promising with respect to Web-based learning. We can conclude that students accept Web classes and perform well in them. Care must be taken, however, in interpreting and extending these conclusions. We really do not have a good comparison between the amount of learning in a conventional class relative to that in the Web class. Grades are an indicator of learning but do not provide an absolute scale. Additionally, there are many forms that a Web class may take and many different audiences. While the results reported here are promising, much more needs to be done before placing Web education into the mainstream of University and College engineering education.

\section{REFERENCES}

1. J. Palais, Fiber Optic Communications, $4^{\text {th }}$ ed., Prentice-Hall, 1998. 